\title{
Endodontic Management of S-Shaped Root Canal in a Maxillary Premolar Using Controlled Memory Nickel Titanium Rotary Files - A Case Report
}

\author{
Shreyal Ninad Deshmukh¹, Vanitha Umesh Shenoy², Sumanthini Venkatsubramanyam Margasahayam³, \\ Anuradha Bhausaheb Patil ${ }^{4}$, Jimish Rajiv Shah ${ }^{5}$ \\ 1, 2, 3, 4, 5 Department of Conservative and Endodontics, Mahatma Gandhi Missions Dental College and Hospital, \\ Kamothe, Navi Mumbai, Maharashtra, India.
}

\section{INTRODUCTION}

Thorough disinfection of the entire root canal is essential for successful endodontic therapy. ${ }^{1}$ Root canal instrumentation and cleaning becomes difficult in the presence of curvature. It is uncommon to observe a tooth with a straight root canal because most teeth exhibit some curvature of the root canal. In addition, most canals have multiple planes of curvature throughout their length. ${ }^{2}$

Routine periapical radiographs can be used for assessment of the length, curvature, and morphologic complexities of the root canal. According to Vertucci, maximum anatomic variations are seen in maxillary premolars, $\mathrm{S}$-shaped or bayonetshaped root canal being the most common. ${ }^{3}$ These root canals have also been reported in maxillary laterals, maxillary canines, and mandibular molars. S shaped canals have at least two curves, with the apical curve being the most vulnerable to deviations which makes them troublesome and challenging. ${ }^{4}$ When a bayonet shaped canal is enlarged, the file binds at the first curve and ledges or starts to perforate at that site. If the operator panics and attempts to force the instrument, the condition will quickly worsen. ${ }^{5}$ Before the advent of nickel titanium instruments, the traditional approach for shaping S shaped canal was to use of a small $\mathrm{H}$ file to reduce middle third curve of the root canal and leaving the apical third to be instrumented. ${ }^{6}$ Recently with advances in metallurgy of nickel titanium files these complex canal curvatures can be efficiently managed. This case report will highlight management of S-shaped canal in permanent maxillary second premolar.

\section{PRESENTATION OF CASE}

A 32-year-old female patient reported to the Department of Conservative Dentistry and Endodontics with a chief complaint of spontaneous dull aching pain in upper right back region of jaw since 1 month. The pain aggravated on mastication and relieved on its own. Medical history of the patient was non-contributory. On examination of the involved region, maxillary left second premolar (15) presented with distal caries and tooth was tender on percussion. On pulp sensibility tests (Digitest II, USA), tooth gave a delayed response as compared to the adjacent tooth. On radiographic examination, 15 presented with a radiolucency involving enamel, dentin and pulp. The root canal presented with an S-shaped root canal curvature with the apical curvature distally. Periapically, there was loss of lamina dura seen. (Figure 1). Hence, a final diagnosis of symptomatic irreversible pulpitis with symptomatic apical periodontitis was arrived at.
Corresponding Author: Dr. Shreyal Ninad Deshmukh, 1303/1, A building Siddhachal, Phase VI, Near Vasant Vihar, Pokhran Road no. 2, Thane - 400607, Maharashtra, India.

E-mail: shreyalndeshmukh@gmail.com

DOI: $10.14260 / \mathrm{jemds} / 2020 / 853$

How to Cite This Article:

Deshmukh SN, Shenoy VU, Margasahayam $S V$, et al. Endodontic management of $S$ shaped root canal in a maxillary premolar using controlled memory nickel titanium rotary files - a case report. J Evolution Med Dent Sci 2020; 9(51):3894-3897, DOI: 10.14260/jemds/2020/853

Submission 26-08-2020,

Peer Review 20-10-2020,

Acceptance 26-10-2020,

Published 21-12-2020.

Copyright (c) 2020 Shreyal Ninad Deshmukhn et al. This is an open access article distributed under Creative Commons Attribution License [Attribution 4.0 International (CC BY 4.0)] 


\section{DISCUSSION OF MANAGEMENT}

With informed consent, local anaesthesia was administered using $2 \%$ lignocaine and 1:200000 adrenaline (Lox $2 \%$, Neon, and Thane, India) and endodontic therapy was initiated. Initially, complete caries excavation was done using sterile round carbide bur (Mani, India) in high speed airotor hand piece (Prefier Dent, India) with water spray. After caries excavation, pulp exposure was seen. Complete de roofing of the pulp chamber was done with safe ended diamond point (EX - 24) (Mani Inc, Japan). After access opening, two canal orifices were observed which united at the apical third presenting a Vertucci Type II canal configuration. (Figure 2). Pre endodontic buildup of distal proximal wall was done with composite resin (Filtek Z350 XT universal restorative, 3M, United States) which was followed by rubber dam isolation (Hygienic, Coltene / WhaledentInc, USA). Orifice enlargement was done with gates Glidden drill No. 3 (Mani Inc, Japan) and profile orifice shaper No. 25 (Dentsply Malleifer, Switzerland). Coronal two third enlargement was achieved with Hyflex Controlled Memory files (Coltene / WhaledentInc, USA) No. 20.04 and 25.04. The canal was scouted with sterile stainless steel K-files No. 08 and 10 (Mani Inc, Japan). Working length determination was done with electronic apex locator (Root ZX, J Morita, and Japan) and was later confirmed with radiographs (Figure 2). Working length for buccal and palatal canal was 18 $\mathrm{mm}$ and $16 \mathrm{~mm}$ respectively. After determination of working length, Proglider file (Dentsply Sirona, Canada) was used in an endomotor (Xmart plus, Dentsply Malleifer, Switzerland) at a speed of $300 \mathrm{rpm}$ and torque of $2 \mathrm{Ncm}$ in light brushing strokes to expand the glide path prepared by hand files. Glide path preparation was further done using NiTi hand files No. 15 and 20 (Endostar, Poldent Co. Ltd, Warsaw) and further cleaning and shaping was carried out using Hyflex Controlled memory files (Coltene / WhaledentInc, USA) up to size 30 (4\% taper) at a speed of $500 \mathrm{rpm}$ and torque of $2.5 \mathrm{~N}-\mathrm{cm}$. In between instrument change, $5 \mathrm{ml}$ of $2.5 \%$ sodium hypochlorite (Trifarma Pvt Ltd, Bhiwandi, and Thane, India) was used as an irrigating solution and patency filing was done along the buccal canal with a sterile stainless steel file $8 \mathrm{~K}$ file. Sterile calcium hydroxide (CH) (Prime Dental Products, Thane, India) mixed with normal saline (Influtec Healthcare Limited, Indore, India) to a thick consistency was used as an intracanal medicament for a period of 15 days.

At the following appointment, $\mathrm{CH}$ was removed from canal by irrigating with normal saline and with help of ultrasonic activation with Irrisafe ultrasonic tip \# 25 (Acteon, Merignac, France).Selection of master cone size 30 (Dentsply Sirona, Canada) with a taper of $4 \%$ was done for both the canals (Figure 3). Obturation was carried out with GP (Gutta-Percha) and AH plus sealer (Dentsply Malleifer, Tulsa, OK) using modified continuous wave compaction technique (Calamus dual, Dentsply Sirona, Australia). Hand pluggers and pluggers of Calamus dual passively fitting $5 \mathrm{~mm}$ short of the estimated working length were selected for both the canals. After coating the canal with sealer, selected master cone was inserted in the canal and lateral compaction was carried out up to $5 \mathrm{~mm}$ from the working length. Calamus Dual was activated and the heated plugger was carried to the premeasured length to sear off the GP. Premeasured hand plugger was used to compact the apical plug of gutta percha) (Figure 4).
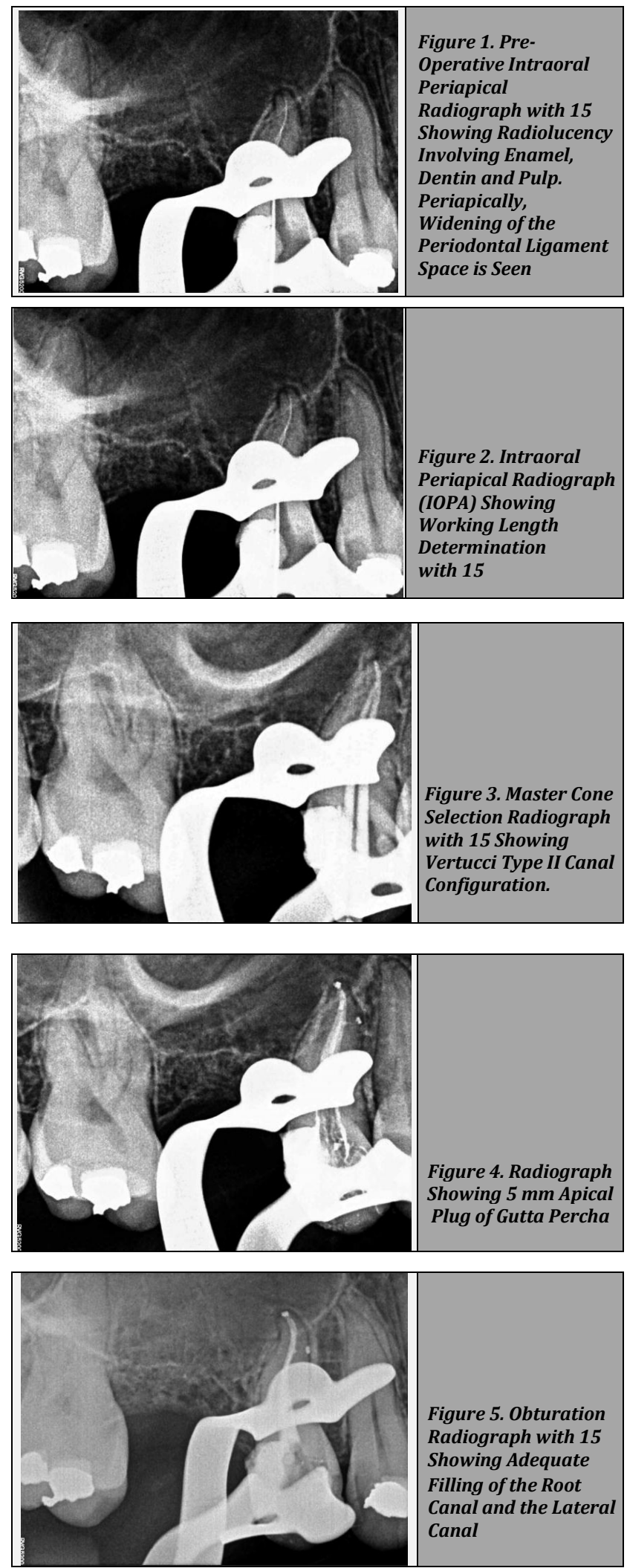

Filling of remaining canal was done with backfill using thermoplasticized gutta percha technique (Denjoy Fastfill, Denjoy Dental Co., Ltd, China) (Figure 5). Following obturation, the canal orifice was sealed with conventional glass ionomer cement (GC Fuji II,GC India, Telangana, India) and access cavity restored with resin composite restoration 
(Filtek Z350 XT universal restorative, 3M, United States). Patient will be recalled at 3 months, 6 months, 9 months and 12 months.

\section{DISCUSSION}

Endodontic diagnosis and treatment present challenges in multirooted teeth. ${ }^{2}$ The final results of the instrumentation of curved root canals depends on flexibility of endodontic instruments, instrumentation techniques, location of the foramina, the hardness of dentin and skill of clinician. ${ }^{7}$ Preparation of curved root canals leads to undesirable occurrences like formation of ledges, blockages, perforations and apical transportation. ${ }^{8}$

Radiographs can be used to identify S shape or doublecurved canals when they are present in a mesial or distal direction. Multiple-angled radiographs can be used to identify if the curvature traverses in a buccal or lingual direction or when the initial apical file is removed from the canal, it depicts multiple curves. ${ }^{4}$ Traditional approach for treating S shaped canal involved use of stainless steel files. In such cases the clinician must skew the access preparation to create an unrestricted approach to the first curve, passive shaping of the coronal curve should be carried out and apical $3 \mathrm{~mm}$ of the stainless steel file should be over curved to maintain the curvature of the apical portion of the canal. ${ }^{4}$ After cleaning the area of the apical foramen, an apical matrix was developed, using instruments that were further modified by blunting the flutes of the outer portion of the curve in the apical segment of the file. The flutes were blunted with a sterile diamond disc or a sandpaper disc. ${ }^{6}$

The coronal one-third of the root canal should be flared to reduce the angle of curvature was suggested by Guttman. 4 After this procedure, the remainder of the root canal can be easily negotiated. ${ }^{4}$ Sakkir $\mathrm{N}$ et al reported a case of $\mathrm{S}$ shaped canal in maxillary second premolar, the case was successfully managed with cleaning and shaping with Hyflex CM files and obturation with lateral condensation technique. ${ }^{9}$

In the present case, orifice enlargement was done with profile orifice shaper no 25 and coronal two third enlargement was done with Hyflex CM rotary files. After which negotiation of the canals was done with stainless steel hand $\mathrm{K}$ files no. 8 and 10 , following which working length determination was done. Once the working length was established with a small file after negotiating the curvature, it must not be removed from the canal but worked in short up and down filing motion until the file is loose in the canal. ${ }^{5}$ However, if the file is removed prematurely, it becomes extremely difficult to gain the correct length with another file, even one of the same size. ${ }^{5}$

In the present case, preparation of glide path was done with Proglider files. ProGlider is a single-use glide path file which is manufactured from M-wire technology with progressive tapered design over the active portion. This design characteristics decreases the possibility for taper lock and the dangerous screw effect. ${ }^{10}$ ProGlider has unique movement, design and metallurgy which removes dentin safer, faster and creates more fully tapered pathway to length compared to a stainless steel size 15 hand file. ${ }^{10}$

Cleaning and shaping of the canals was carried with Hyflex Controlled Memory files in the present case. They are manufactured by CM wire technology. ${ }^{11}$ Controlled Memory NiTi (Nickel Titanium) files are extremely flexible but without the shape memory of other NiTi instruments. Memory of the material is controlled by a special thermomechanical process.

These files have high resistance to fracture, and they respond to pressure, torque, and resistance with a lengthening of the spirals. Due to this risk of iatrogenic mishaps is reduced and the file follows the anatomy of the canal very closely. ${ }^{11}$

In the present case, modified continuous wave compaction technique was used for obturation of canal. The warm guttapercha method is specifically indicated when maximum condensation is desired ${ }^{12}$ or in cases when there is ledge formation, perforation, or unusual canal curvature. ${ }^{13}$ The use of a single cone with the consequent absence of compaction of the material against the root canal walls, showed that the probability to form gaps. ${ }^{14}$

\section{CONCLUSIONS}

Thorough disinfection and obturation of severe root canal curvatures pose substantial difficulty. In the management of curved canals, knowledge of internal canal morphology and appropriate instrumentation techniques is essential to prevent complications.

Financial or other competing interests: None.

Disclosure forms provided by the authors are available with the full text of this article at jemds.com.

\section{REFERENCES}

[1] Ingle JI, Bakland LK. Ingle's Endodontics 6. $6^{\text {th }}$ edn. Hamilton, Ontario: BC Decker Inc 2008: p. 877.

[2] Cohen S, Burns RC. Pathways of the pulp. $10^{\text {th }}$ edn. St Louis: Mosby 2002: p. 289.

[3] Vertucci FJ. Root canal anatomy of the human permanent teeth. Oral Surg Oral Med Oral Pathol 1984; 58(5):589-99.

[4] Guttman JL. Problem solving in endodontics. $5^{\text {th }}$ edn. Missouri: Mosby 2011. p. 267.

[5] Wiene FS. Endodontic therapy. $6^{\text {th }}$ edn. St. Louis: Mosby 2004: p. 617-8.

[6] Grossman LI, Oliet S, Del Rio CE. Grossman's Endodontic practice. 11 $1^{\text {th }}$ edn. Philadelphia, PA: Lea \& Febiger 1988.

[7] Mounce R. Negotiating challenging mid root curvatures: rounding the bend. Dent Today 2007; 26(2):108-12.

[8] Hamasha AA, Al-Khateeb T, Darwazeh A. Prevalence of dilaceration in Jordanian adults. Int Endod J 2002; 35(11):910-2.

[9] Sakkir N, Thana KA, Nair MG, et al. Management of dilacerated and S-shaped root canals - an endodontist's challenge. J Clin Diagn Res 2014; 8(6):ZD22-4.

[10] Proglider brochure. http://www.dentsplymaillefer.com/ wp-content/uploads/2015/07/PROGLIDERTULSA_0515_DFU_EN.pdf

[11] Hyflex $\quad \mathrm{Cm}$ https://www.coltene.com/pim/DOC/BRO/docbro684603-18-en-hyflex-cm-edm-a4senaindv1.pdf

[12] Cohen S, Burns RC. Pathways of the pulp. $11^{\text {th }}$ edn. St. Louis, Missouri: Mosby 2016: p. 305. 
[13] Ingle JI, Bakland LK. Endodontics. $5^{\text {th }}$ edn. Hamilton, Ontario: BC Decker Inc., 2008: p. 619.
[14] Hammad M, Qualtrough A, Silikas N. Evaluation of root canal obturation: a three dimensional in vitro study. J Endod 2009; 35(4):541-44. 